\title{
Study of matrix micro-cracking in nano clay and acrylic tri-block-copolymer modified epoxy/basalt fiber-reinforced pressure-retaining structures
}

\author{
M. Bashar ${ }^{1}$, U. Sundararaj ${ }^{2}$, P. Mertiny ${ }^{1 *}$ \\ ${ }^{1}$ University of Alberta, Department of Mechanical Engineering, 4-9 Mechanical Engineering Building, Edmonton AB, \\ T6G 2 G8 \\ ${ }^{2}$ University of Calgary, Department of Chemical and Petroleum Engineering, 2500 University Drive NW, Calgary AB, \\ T2N $1 \mathrm{~N} 4$
}

Received 9 January 2011; accepted in revised form 13 April 2011

\begin{abstract}
In fiber-reinforced polymer pressure-retaining structures, such as pipes and vessels, micro-level failure commonly causes fluid permeation due to matrix cracking. This study explores the effect of nano-reinforcements on matrix cracking in filament-wound basalt fiber/epoxy composite structures. The microstructure and mechanical properties of bulk epoxy nanocomposites and hybrid fiber-reinforced composite pipes modified with acrylic tri-block-copolymer and organophilic layered silicate clay were investigated. In cured epoxy, the tri-block-copolymer phase separated into disordered spherical micelle inclusions; an exfoliated and intercalated structure was observed for the nano-clay. Block-copolymer addition significantly enhanced epoxy fracture toughness by a mechanism of particle cavitation and matrix shear yielding, whereas toughness remained unchanged in nano-clay filled nanocomposites due to the occurrence of lower energy resistance phenomena such as crack deflection and branching. Tensile stiffness increased with nano-clay content, while it decreased slightly for block-copolymer modified epoxy. Composite pipes modified with either the organic and inorganic nanoparticles exhibited moderate improvements in leakage failure strain (i.e. matrix cracking strain); however, reductions in functional and structural failure strength were observed.
\end{abstract}

Keywords: polymer composites, epoxy nanocomposites, filament winding, fracture toughness, matrix cracking

\section{Introduction}

Filament winding is known to be one of the most economic and efficient methods for producing fiberreinforced polymer (FRP) structures such as pipes and vessels. Pressure-retaining structures made from FRP are becoming increasingly popular, and are frequently considered as an alternative to conventional metallic structures. Improved performance in terms of high specific strength and corrosion resistance can be achieved with FRP pressure structures. However, the performance of these structures is dependent on the diverse and sustained loading conditions throughout their service life. It is there- fore of great importance to understand their complex material behavior and damage mechanisms under different loading conditions and environmental effects.

In the design and application of composite pressure piping, functional and structural failure mechanisms must be considered [1-6]. In the case of functional failure (e.g. leakage) the structure is unable to contain the pressurized fluid, even though it is still able to sustain the applied mechanical loading. Structural failure (e.g. burst failure) is thus characterized by the pipe's inability to carry the applied loading. These types of failure usually occur as sep-

\footnotetext{
${ }^{*}$ Corresponding author, e-mail: pmertiny@ualberta.ca
}

(c) BME-PT 
arate events, but can happen as concomitant damage events depending on the applied loading situation. Functional failure is typically distinguished by fluid weepage and wetting of the outer wall. Due to fluid transmission through the wall, composite pressure structures have restricted application without any ancillary support medium (e.g. liner). Leakage is directly related to transverse matrix microcracking which is characterized by a reduction of composite stiffness as well as nonlinear stress-strain behavior. Functional failure is known to occur when transverse tensile loading normal to the fibers exceeds a certain threshold value [6].

Thermosetting polymers such as epoxy with their inherent brittleness are particularly prone to matrix cracking. One possible route to enhance ductility of thermosets is by dispersing rubbery phases inside the polymer matrix, i.e. liquid rubbers [7-13], thermoplastic spheres $[14,15]$, core-shell particles [1618] and nanostructured block-copolymers [19-23]. Likewise, inorganic particles such as silica [7, 24], alumina [24], glass beads [25] and nano-clay [18, 26-30] are also known to enhance the toughness of the epoxy. Mechanism of epoxy toughening (i.e. particle cavitation, matrix shear yielding, multiple crazing, crack pinning and crack deflection) can be as diverse as the multifarious reinforcements available [31]. Irrespective of the operative resistance mechanism, the sole purpose of the dispersant is to aid the deformation process for dissipating energy. In FRP structures the presence of a fibrous reinforcement phase introduced additional complexity to polymer toughening. It is peculiar that toughness enhancements as observed in bulk polymers are not always transferrable to the same extent to fiber composite systems [32, 33].

Recently, polymer nanocomposites have become the forefront of composite research. Polymer nanocomposites are typically composed of a polymeric phase with one or more reinforcing nano-scale materials. Final properties of the resulting nanocomposites are dependent on the type of constituents used, their morphologies, interfacial characteristics, dispersion methods and preparation techniques. The nano-clay I.30E used in this study is an organically modified hydrous aluminosilicate with a platelike structure, having an aluminum octahedron layer sandwiched between silicon tetrahedron sheets. Studies have indicated that optimum properties of the resulting nanocomposite are obtained in an exfoliated structure, when individual silicate layers are completely dispersed into the polymer matrix [3436]. The distance between the clay interlayer in the polymer matrix depends on such properties as the clay structure, curing agent, curing temperature and time, viscosity and the type of resin. Block-copolymers on the other hand have a structure consisting of rather long sequences of different repeating units. Commercially available M52N is an acrylic triblock-copolymer which consists of rigid and rubbery blocks. This type of block-copolymer easily dissolves in epoxy resin and self-assembles on the nanolevel due to the affinity between epoxy monomers and polymethylmethacrylate (PMMA), and repulsion between the epoxy monomers and the middle polybutylacrylate block (PBuA) [21, 22]. Various studies have been conducted on block-copolymer modified epoxy, most of which reported enhancements in toughness and ductility in the modified resin, while causing only minor reductions in stiffness and strength [19-23]. Similarly, nano-clay filled nanocomposites were found to increase toughness as well [26-29]. In clay modified materials an enhanced tensile strength and stiffness [26, 27, 34] were usually also observed while ductility was compromised.

The focus of the present study is to investigate methods for enhancing mechanical properties of the epoxy matrix by incorporating nanoparticles into the material system. The notion is to improve matrix toughness by adding nanoparticles into the substrate material to mitigate or prevent transverse matrix cracking in filament-wound pressure-retaining structures. With this intention in mind, two different types of nanoparticles were investigated, i.e. inorganic clay I.30E and organic tri-block-copolymer M52N. Several epoxy-nanoparticle formulations were developed and used as the matrix material for filamentwound composite piping. Morphology, mechanical and fracture studies of bulk epoxy nanocomposites were performed, and hybrid filament-wound epoxy composite pipes were subjected to biaxial stress testing.

\section{Experimental procedure \\ 2.1. Material system}

The matrix material used in this study was EPON 826 bisphenol-A resin with EPI CURE 9551 non- 
MDA polyamine curing agent; both are proprietary formulations of Hexion Specialty Chemicals (Columbus, Ohio, USA). The nanofiller used was Nanomer I. $30 \mathrm{E}, \mathrm{CH}_{3}\left(\mathrm{CH}_{2}\right)_{17} \mathrm{NH}_{3}$-MMT, which is an primary alkylammonium ion modified Na-montmorillonite (Na-MMT) from Nanocor Inc. (USA). The other type of nano-phase material was an acrylic tri-blockcopolymer M52N [PMMA/DMA PBuA PMMA/ DMA] (where DMA stands for dimethacrylamide) synthesized by Arkema Inc. (Philadelphia, Pennsylvania, USA). The fiber reinforcement material was basalt fiber KV12 supplied by Kamenny Vek (Dubna, Moscow Region, Russia).

\subsection{Epoxy nanocomposite formulation}

Preparation and processing of epoxy nanocomposites from resin, curing agent and nanofillers involved such major steps as mixing, dispersion and degassing. Prior to dispersion into the epoxy precursor, nanoclay I.30E was dried in an oven at an elevated temperature of $120^{\circ} \mathrm{C}$ for a period of 24 hours. Afterwards, the nano-clay was allowed to cool down to room temperature. A specific amount of I.30E was first introduced into acetone, and pre-swelling in acetone was performed for six hours at room temperature. The solution was then mixed with preheated EPON 826 resin at $60^{\circ} \mathrm{C}$ by gentle stirring. Acetone promoted migration of epoxy inside the clay interlayer and also reduced resin viscosity. To obtain the desired level of resin viscosity for efficient ultrasonic mixing, the system temperature was slowly raised to $80^{\circ} \mathrm{C}$. A $300 \mathrm{ml}$ mixture of nanoclay and EPON 826 was subjected to sonication in a glass beaker for eight hours. The Sonifier (Branson model S-75) (Branson Ultrasonics Corporation, Danbury, CT, USA) operated at $75 \mathrm{~W}$ power output with $20 \mathrm{kHz}$ output frequency. A step horn sonotrode with a $12.7 \mathrm{~mm}$ tip diameter was used to transmit ultrasonic energy. Sonication was followed by two hours of mechanical mixing. Finally, the mixture was degassed under vacuum until all excess acetone was completely stripped off from the solution.

M52N copolymer was dissolved directly by gradually adding block-copolymer powder to the epoxy resin at room temperature under steady mixing. The temperature was then increased and held stationary at $80^{\circ} \mathrm{C}$ until a homogenous solution and good optical transparency was observed. The dissolution time varied with copolymer concentration.
A stoichiometric amount of curing agent was mixed with the epoxy-nanofiller mixture at $60^{\circ} \mathrm{C}$ for five minutes by a mechanical stirrer running at $900 \mathrm{rpm}$. Formation of bubbles during curing agent addition necessitated a degassing cycle to be performed for 10 20 minutes. Finally, the resin mixture was poured into a stainless steel mold and cured at $120^{\circ} \mathrm{C}$ for two hours. Representative techniques were followed for epoxy nanocomposite formulations containing 1,2 and $3 \mathrm{wt} \% \mathrm{I} .30 \mathrm{E}$ or 1,3 and $5 \mathrm{wt} \%$ M52N.

\subsection{Hybrid nanocomposite pipe fabrication}

Filament-wound basalt fiber/epoxy/nanoparticle tubes were manufactured containing various concentrations of either M52N or I.30E. Hybrid fiberreinforced nanocomposite pipes were fabricated by pulling five continuous basalt fiber strands from their creels using a computer controlled WMS 4axis filament winding machine (McClean Anderson, Schofield, WI, USA). While en-route to the mandrel, fiber strands were thoroughly impregnated with epoxy-nanoparticle formulation contained in a drum-type resin bath maintained at $30^{\circ} \mathrm{C}$. Layers of resin wet fiber material were wound successively onto chrome-plated steel mandrels. Throughout the manufacturing process a numerically controlled tensioning system steadily applied $26.7 \mathrm{~N}$ tension to each fiber strand. Curing of the specimens occurred at $80^{\circ} \mathrm{C}$ for one hour and $120^{\circ} \mathrm{C}$ for 2.5 hours, followed by cooling down to room temperature. For

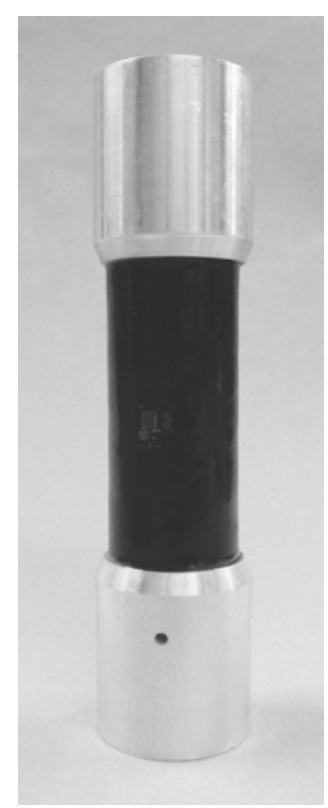

Figure 1. Tubular test specimen 
mechanical testing, a rubber bladder liner was inserted inside each tubular specimen and the tube extremities were reinforced with aluminum end connections. The rubber bladder was designed to enable the assessment of functional as well as structural failure in the same experiment [5]. Composite pipes were also fitted with two strain gauge rosettes aligned parallel and perpendicular to the tube axis. All specimens had a $\left[ \pm 60_{3}\right]_{\mathrm{T}}$ fiber architecture, an inside diameter of $38.1 \mathrm{~mm}$ and a gage length of $90 \mathrm{~mm}$. Figure 1 shows a test specimen with attached aluminum end connections.

\subsection{Microstructure study}

$\mathrm{X}$-ray diffraction (XRD) analysis of the clay nanocomposites was carried out using a Rigaku Geigerflex 2173 (Rigaku Corporation, Tokyo, Japan) diffractometer with a vertical goniometer. The system is equipped with a Co tube and a graphite monochromator to filter K-beta wavelengths. All tests were run at $40 \mathrm{kV}$ and $30 \mathrm{~mA}$, and samples were scanned between $2 \theta=1$ to $30^{\circ}$ changing the angle of incidence at a rate of $0.0082 \theta \mathrm{s}^{-1}$.

Thin sections $(5 \sim 10 \mu \mathrm{m})$ of the epoxy nanocomposite fracture surface were investigated by transmission optical microscopy (TOM). To prepare the thin sections, nanocomposite blocks were first placed in a Reichert Jung Ultra Microtome (C. Reichert Optische Werke AG, Vienna, Austria) and sectioned

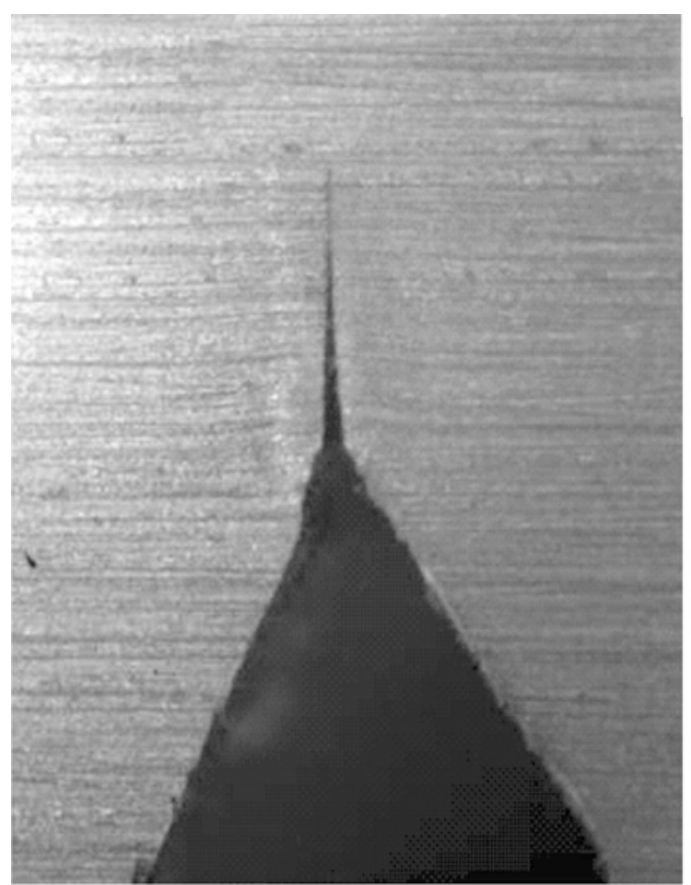

a) with a diamond cutter. These sections represent an area near the starter crack taken normal to the fracture surface and parallel to the crack propagation direction. The subsurface birefringent zone was explored under bright field and between cross polarizers using a Leica DMRXA microscope (Leica Microsystems, Wetzlar, Germany) directly connected to a Nikon DXM 1200 digital camera.

Representative samples of the cured nanocomposites having a thickness of about $40 \mathrm{~nm}$ were examined with a Morgagni 268 (FEI, Hillsboro, Oregon, USA) transmission electron microscope (TEM) at $80 \mathrm{kV}$. A Reichert Jung Ultra Microtome was again used to make the thin specimens. Some of the nanocomposite samples containing M52N block-copolymer were allowed to stain overnight in $4 \%$ osmic acid.

\subsection{Mechanical testing of epoxy nanocomposites}

Stress intensity factors $K_{\mathrm{I}}$ at failure of nanocomposite samples under plane-strain conditions were determined by three-point bending. The single edge notch bend (SENB) geometry was chosen according to the standard ASTM D5045 99, and testing was performed on a MTS 810 (MTS Systems Corporation, Eden Prairie, MN, USA) universal testing machine with a crosshead speed of $0.2 \mathrm{~mm} / \mathrm{min}$. Two methods were chosen to pre-crack specimens

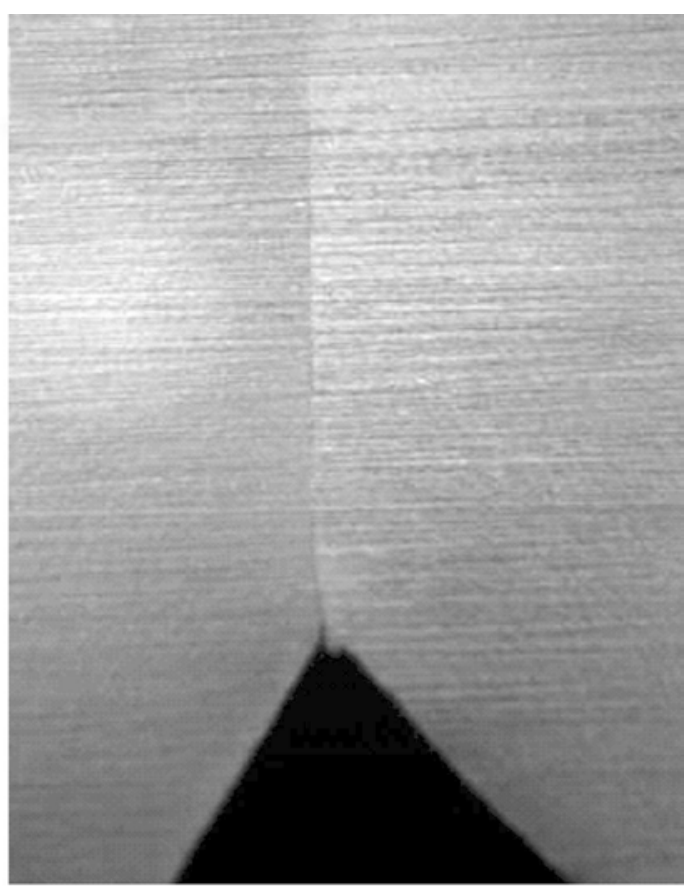

b)

Figure 2. Pre-crack configurations: (a) blunt crack, (b) sharp crack [35] 
prior to testing. A razor blade was inserted and pressed down to a depth of $1 \mathrm{~mm}$ inside a machined notch using the same MTS machine. This generated a blunt crack as shown in Figure 2a. The second method involved inserting and repeatedly tapping a razor blade with a hammer into the machined notch, which created a natural sharp crack (see Figure 2b). The stress intensity factor was calculated according to Equations (1-3):

$K_{\mathrm{I}}=\frac{P}{B W^{1 / 2}} f(x)$

with

$x=\frac{\alpha}{W}$

$f(x)=6 x^{1 / 2} \cdot \frac{1.99-x(1-x)\left(2.15-3.93 x+2.7 x^{2}\right)}{(1+2 x)(1-x)^{3 / 2}}$

where $P$ is the load at failure, $B$ is the specimen thickness, $W$ is the specimen width, and $\alpha$ is the overall crack length. In this study, stress intensity factors of sharp pre-cracked specimens were considered to provide the fracture toughness $K_{\mathrm{IC}}$ of the composite.

Uniaxial tensile tests were performed according to the standard ASTM D638 03 for the determination of the tensile modulus, tensile strength and tensile elongation at break of the neat epoxy and the nanocomposite samples. Dog bone specimens were mounted into the MTS 810 universal testing machine, and tested at a constant loading rate of $4.5 \mathrm{~N} / \mathrm{s}$.

\subsection{Fractographic study}

Fracture surfaces of single edge notch bend specimens were explored by a JEOL $6301 \mathrm{~F}$ field emission scanning electron microscope (SEM) (JEOL Ltd., Tokyo, Japan) at an accelerating voltage of $5 \mathrm{kV}$. This instrument allowed for nanostructure evaluation with a high resolution of approximately $\sim 3 \mathrm{~nm}$. Before inspection, a conductive gold coating was applied to the I.30E nanocomposite fracture surface, while M52N modified epoxy fracture surface was coated with chromium.

\subsection{Mechanical testing of hybrid nanocomposite tubes}

Prior to mechanical testing of the hybrid fiber-reinforced nanocomposite pipes, fiber volume fractions were determined by resin burn-out tests, and nominal wall thicknesses were also calculated [6]. Corresponding data is summarized in Table 1. Tube samples made with M52N and I.30E exhibited, for the most part, decreasing fiber volume fraction with increasing nanofiller content. The reverse trend resulted for the wall thicknesses, which increased with rising nanofiller content. An increase in resin viscosity with nanofiller loading is assumed to have caused this behavior.

Multi-axial testing of the pipe specimens was performed by applying a monotonic 2-to-1 hoop-toaxial stress loading ratio ('pressure vessel loading') [2]. During each test a custom built multi-axial testing machine maintained a constant biaxial stress ratio by simultaneously applying internal pressurization and axial traction. All tests were preformed under load control conditions. A pressure intensifier supplied hydraulic oil for specimen pressurization at a rate of $4.63 \mathrm{kPa} / \mathrm{s}$. Loading was continued until ultimate specimen failure (i.e. structural failure). The data acquisition system permitted recording of hoop and axial strains, axial load and stroke, internal pressure and pressure intensifier volume. Average hoop and axial stresses were determined applying thin-wall membrane theory according to standard ASTM D2992 06. Hoop and axial stresses were calculated according to Equations (4) and (5):

$$
\begin{aligned}
& \sigma_{\mathrm{H}}=\frac{D\left(p_{\mathrm{i}}-p_{0}\right)-2 t p_{0}}{2 t} \\
& \sigma_{\mathrm{A}}=\frac{D^{2}\left(p_{\mathrm{i}}-p_{0}\right)-4 t p_{0}(D+t)}{4 t(D+t)}+\frac{F}{\pi t(D+t)}
\end{aligned}
$$

Table 1. Fiber volume fraction and nominal wall thickness for fiber-reinforced nanocomposite pipes

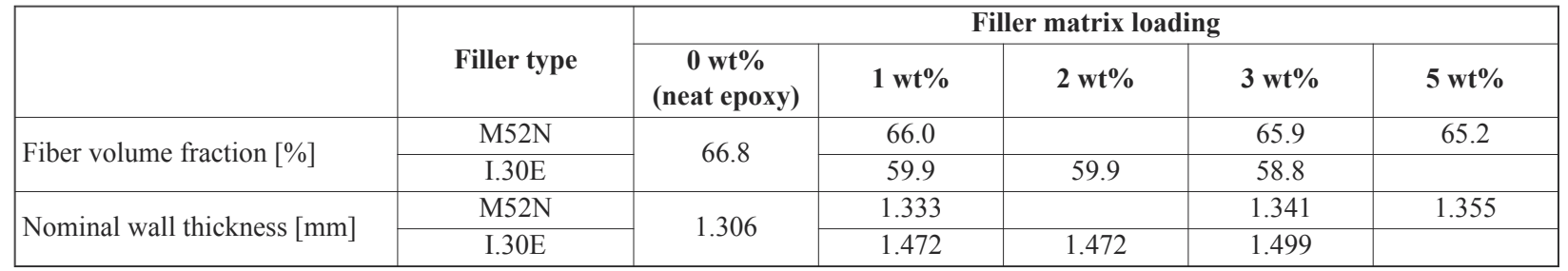


where $D$ is the internal pipe diameter, $t$ is the wall thickness, $p_{\mathrm{i}}$ and $F$ are the internal pressure and axial force applied to the pipe, and $p_{0}$ is the atmospheric pressure.

\subsection{Detection of pipe failures}

Quantification of previously mentioned failure events was critical as this would typically standardize the performance of the composite pipes for their intended service condition. To identify functional and structural failure events from the same test setup, each pipe sample was fitted with the aforementioned internal rubber bladder, which enabled pressurization until catastrophic pipe failure. Prior to testing the inside of a rubber bladder as well as the annular volume in between the pipe and the bladder were filled with hydraulic fluid. Pressurization occurred from inside the bladder. In the course of the experiment, the initiation, accumulation and coalescence of matrix cracks provided pathways for fluid to escape through the composite structure. In this study, functional failure in the form of leakage was characterized by a prescribed fluid loss volume through the tube wall (i.e. a loss corresponding to $1 \%$ of the internal pipe volume). After a certain amount of fluid loss from the annulus, the inflating rubber bladder provides a seal inside the specimen. Pressurization was continued until rapid loss of fluid from the hydraulic system was ascertained indicating pipe burst, i.e. structural failure.

\section{Results and discussion}

\subsection{Microstructure study}

The morphology of the layered silicate in nanocomposites was studied by wide-angle $\mathrm{X}$ ray diffraction (WAXD). X-ray diffraction patterns of cured nanocomposites for various clay loadings are shown in Figure 3. Nanocomposites containing 1 and $2 \mathrm{wt} \%$ I.30E clay did not produce any distinguishable diffraction peak. In these nanocomposites the clay architecture can therefore be interpreted as exfoliated. Nevertheless, an intercalated structure cannot be fully ruled out as the traces exceed the detection limit of the WAXD $\left(2 \theta \geq 1^{\circ}\right)$. Also shown in Figure 3 is the diffraction peak for a sample with $3 \mathrm{wt} \%$ clay, which shifted to the left implying that the clays preserved their characteristic stacked layer structure as tactoids with interlayer spacing $d_{001}$ of $2.72 \mathrm{~nm}$. From XRD traces the interlamellar dis-

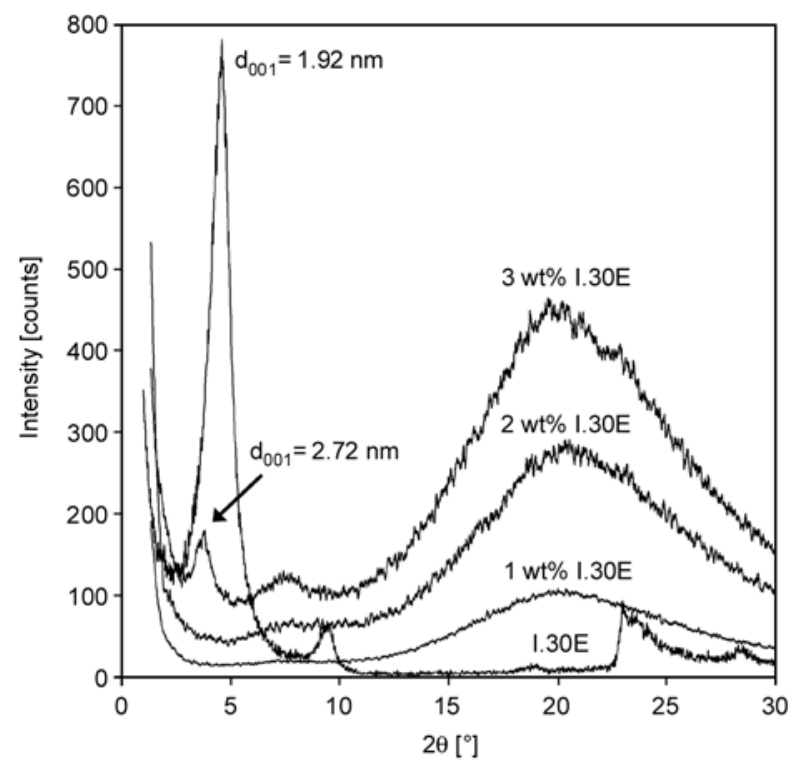

Figure 3. X-ray diffraction traces of pure I.30E and its nanocomposites

tance of the pure organically modified clay I.30E was estimated to be $d_{001}=1.9 \mathrm{~nm}$.

The TEM micrograph of a clay nanocomposite shown in Figure 4a displays partly exfoliated and predominantly intercalated layered silicate structures having adjacent silicate layers $10 \sim 15 \mathrm{~nm}$ apart from each other. Although most of the intercalated nano-clays are in submicron size, a few agglomerated micron size clay particles are also visible in the TEM micrograph, as exhibited in the lower magnification image of Figure $4 \mathrm{~b}$. In agreement with Messersmith and Giannelis [36] it was assumed that this type of aggregate formation is the result of chemical interaction between the silicate layer and the $\mathrm{N}-\mathrm{H}$ group in the polyamine curing agent or from the alkyl ammonium ion modifier of the nanoclay. Figures $4 \mathrm{c}$ and $4 \mathrm{~d}$ show randomly dispersed 20 30 nm spherical micelles of the block-copolymers, which consist of a PBuA rubbery core surrounded by a PMMA rigid shell [22]. Note that consistent with the particle size of both M52N and I.30E and the wavelength of visible light, the prepared nanocomposite samples were optically transparent.

Transmission optical microscopy allowed visualization of polymer deformation by identifying the birefringence and voided zone underneath the fracture surface. Assuming that a propagating crack would leave behind traces of a subsurface damage zone, TOM was employed to confirm the presence 


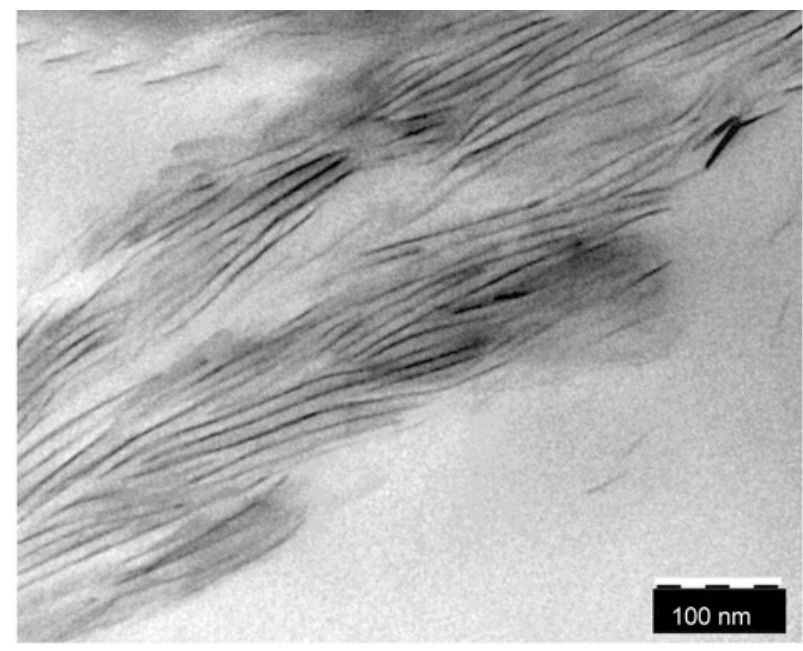

a)

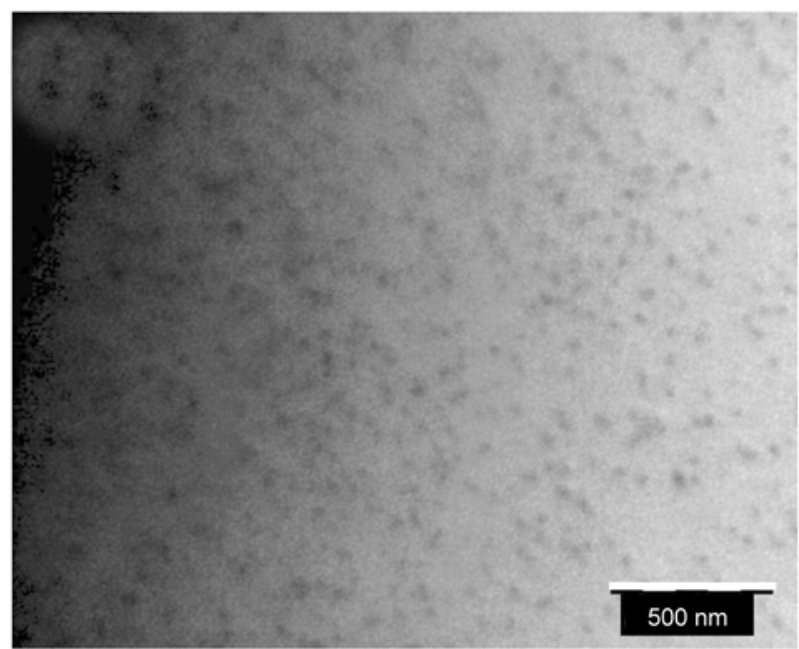

c)

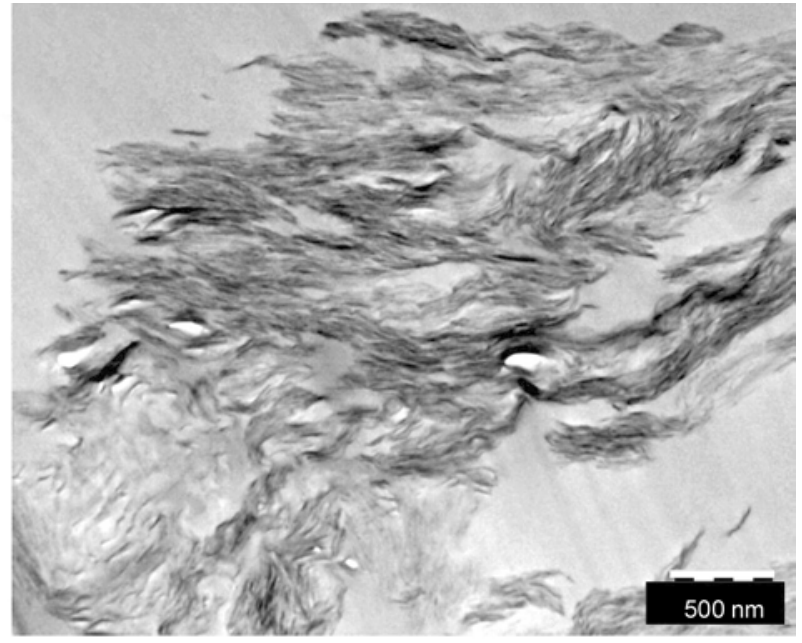

b)

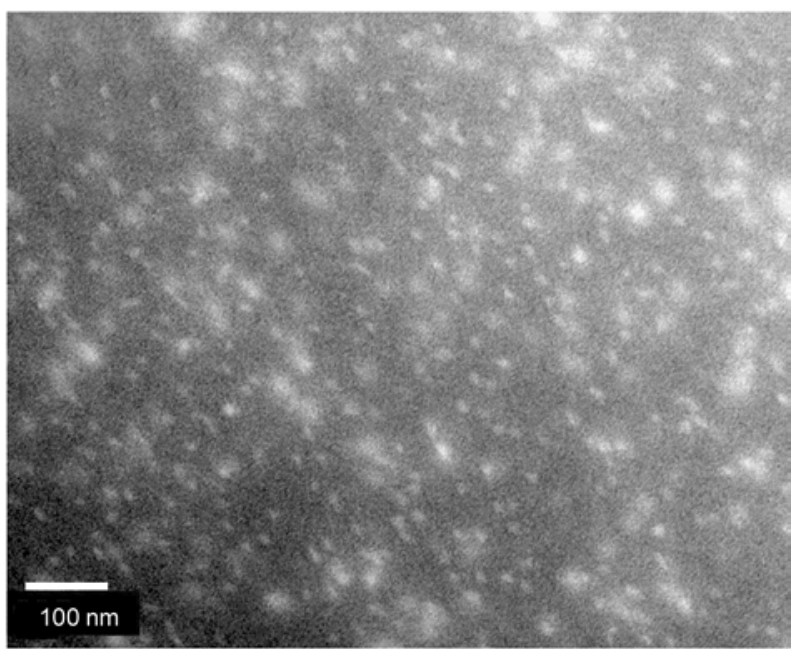

d)

Figure 4. TEM images of nanostructures in epoxy nanocomposites: (a) intercalated clay I.30E (high magnification), (b) flocculated clay I.30E (low magnification), (c) spherical micelles of M52N block-copolymer without osmic acid staining and (d) with osmic acid staining

of the plastic zone. Figure 5 shows the existence of matrix deformation or shear banding for both precrack geometries under plane-strain condition. The birefringent region in the sharp crack is mainly confined in the process zone near the starter crack (see Figure 5b), whereas for the blunt crack the birefringent region shown in Figure $5 \mathrm{c}$ traverses the whole cross-section due to crack-tip plasticity. Dean and coworkers [19, 20] and Hydro and Pearson [21] reported similar subsurface localized matrix deformation for block-copolymer (i.e. PEO-PEP, PMMAPBuA-PMMA) modified epoxy. TOM images taken under bright field and also in cross-polarized light conditions represent a toughened epoxy containing $1 \mathrm{wt} \% \mathrm{M} 52 \mathrm{~N}$. The size of the crack-tip plastic zone can be estimated theoretically according to the Irwin equation [7]. In a plane-strain condition, the Irwin equation, i.e. Equation (6) yields the radius of the plastic zone according to the following expression:

$r_{\mathrm{y}}=\frac{1}{6 \pi}\left(\frac{K_{\mathrm{IC}}}{\sigma_{\mathrm{ys}}}\right)$

where $r_{\mathrm{y}}$ is the radius of the plastic zone, $K_{\mathrm{IC}}$ is the plane-strain fracture toughness, and the value of the tensile yield stress $\sigma_{\mathrm{ys}}=72.76 \mathrm{MPa}$ was measured from uniaxial tensile testing. Theoretically determined radii of the plastic zone are 7.52 and $80.04 \mu \mathrm{m}$ for the sharp and blunt crack geometry respectively. In terms of the linear elastic fracture mechanics, the stress situation at the crack-tip can adequately explain the damage behavior as observed by TOM microscopy. In plane-strain condition, a triaxial state of stress caused an intense stress field at the sharp crack-tip, thereby imposing restrictions 


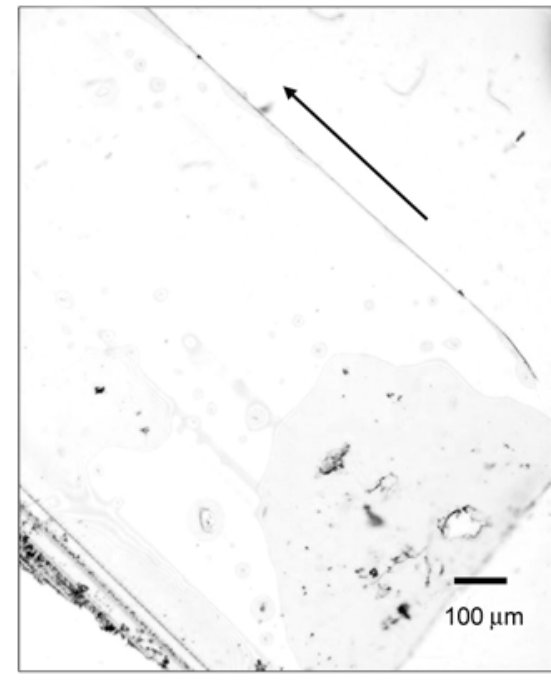

a)

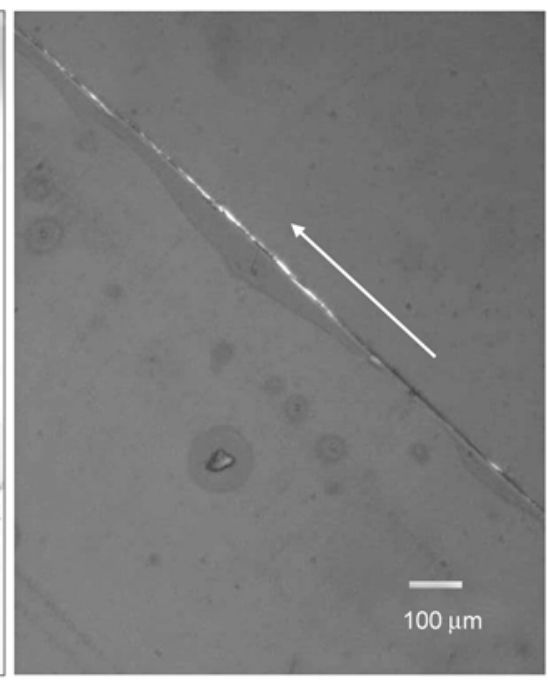

b)

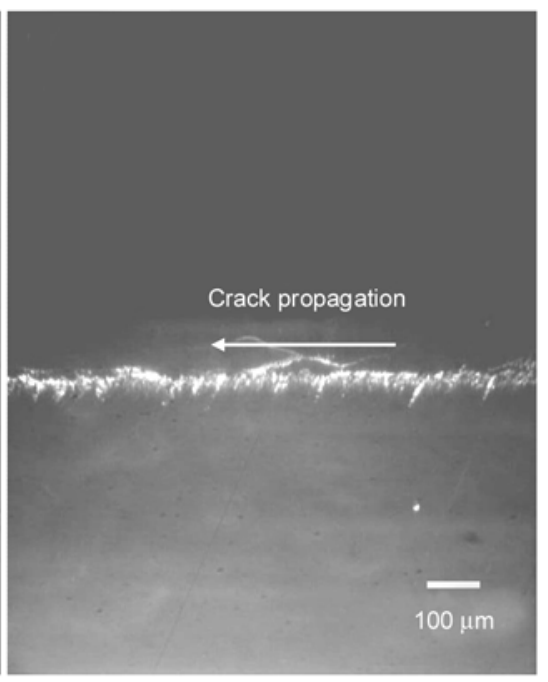

c)

Figure 5. TOM images of epoxy block-copolymer nanocomposites: sharp pre-cracked fracture surface examined under (a) bright field, (b) cross-polarized light and (c) blunt pre-cracked surface under cross-polarized light

on the plastic zone size. For the blunt crack-tip the stress is distributed over a wider section (mimicking a state of plane-stress) that contributed to the formation of a relatively larger plastic zone. Later in this paper it will be shown that these differences in the stress field have a considerable effect on the toughening mechanism of the modified epoxy.

\subsection{Mechanical testing of epoxy nanocomposites}

Fracture toughness of the neat epoxy was estimated to be $0.78 \mathrm{MPa} \cdot \mathrm{m}^{0.5}$. In Figures 6 and 7 average stress intensity factors of neat epoxy and its nanocomposites are compared for the respective pre-crack geometries. (Note that in the following, error bars

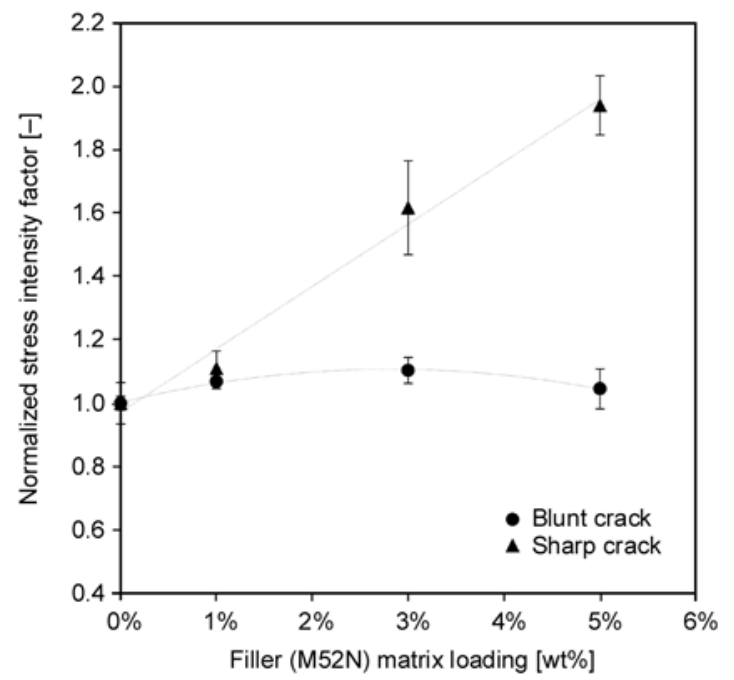

Figure 6. Critical stress intensity factor of nanocomposites relative to M52N block-copolymer concentration shown in graphs represent plus and minus one standard deviation for tests performed in triplicate or greater; lines represent first or second degree polynomial trend lines). It is shown that a sharp precracked nanocomposite containing $5 \mathrm{wt} \% \mathrm{M} 52 \mathrm{~N}$ yields an almost twofold improvement in toughness, which reveals a direct contribution of blockcopolymer loading on fracture toughness. Pearson and Yee $[12,13]$ observed cavitation induced plastic deformation for rubber toughened epoxy, and Wu et al. [23] described a similar crack resistance phenomenon for nanostructured (micelle) blockcopolymer modified epoxy. The present authors also observed similar phenomena during the fracture process. Hydrostatic tension ahead of the sharp

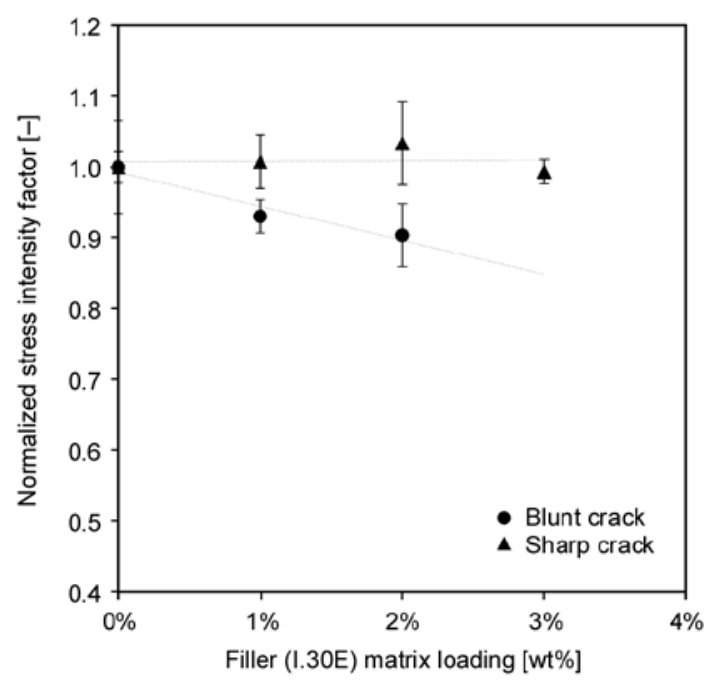

Figure 7. Critical stress intensity factor of nanocomposites relative to I.30E nano-clay concentration 
crack-tip caused cavitation of the rubbery core of the block-copolymer resulting in localized shear deformation of the epoxy matrix; both are energy absorption mechanisms. In the case of blunt cracks only a minor enhancement in critical stress intensity became obvious (see Figure 6), which is assumed to be the effect of crack-tip plasticity evidenced by a large deformation zone shown in TOM microscopy in Figure 5c. Thus, without any discernible distinction in fracture energy between the block-copolymer modified epoxy and the neat epoxy the behavior with a blunt crack practically resembles tensile fracture. Subramaniyan and Sun [29] documented an equivalent effect of crack-tip zone plasticity in their study of organoclay and core-shell rubber toughened epoxy.

As presented in Figure 7 the behavior of nano-clay modified nanocomposites was rather different. For instance, only marginal or no improvement in fracture toughness was achieved for nanocomposites with $2 \mathrm{wt} \%$ I.30E and a sharp crack, and for samples with a blunt crack a moderated drop in fracture energy of up to $10 \%$ was observed. According to Zilg et al. [26] and Zerda and Lesser [27], a mostly intercalated structure rather than an exfoliated nanocomposite improves toughness by exposing additional surface area during the crack propagation process. However, clay nanocomposites prepared in this study behaved differently, primarily due to partial exfoliation of the nano-clay, and secondly, because of the relatively small size of the intercalated nano-clay. It will subsequently be shown (i.e. in Figures 10b and 10c) that most of the particles are indistinguishable on the micron level, indicating a rather uniform distribution of submicron size particles. The ultrasonic mixing process is considered to be the cause for the break down of clay agglomerates into the submicron size. It is well recognized that particle size, shape and structure significantly affect the fracture process in particulate reinforced polymers. In the subsequent section of this paper, micromechanisms are further explored and discussed in light of the insignificant effect of nanoclay on fracture toughness.

Tensile moduli of the neat epoxy and the nanocomposites are shown in Figure 8. In the case of acrylic block-copolymer modified epoxy, the modulus slightly decreased in response to increasing M52N concentration. A decrease of about $5 \sim 10 \%$ was

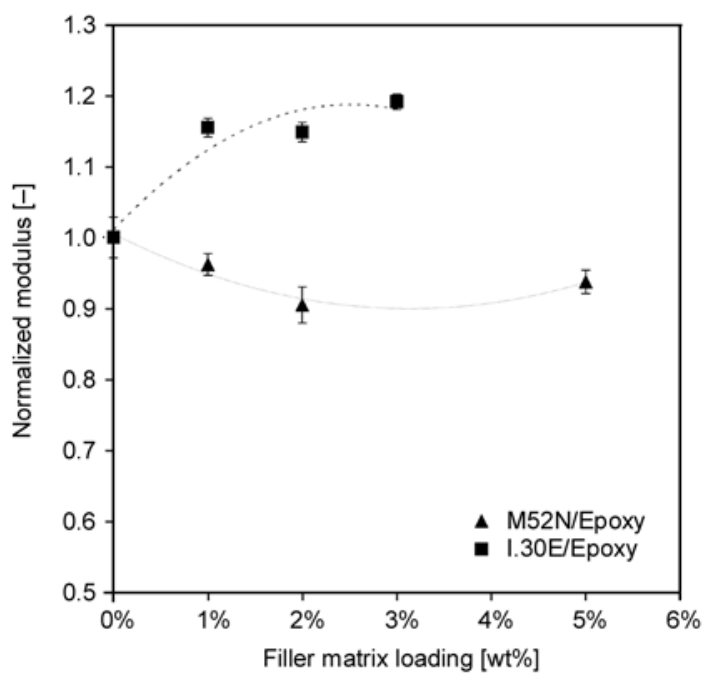

Figure 8. Tensile modulus of nanocomposites with respect to nanofiller loading

observed for the range of M52N concentrations studied. Nanocomposites made from $1 \mathrm{wt} \%$ layered silicate I.30E resulted in more than $16 \%$ enhancement in stiffness compared to pure epoxy; moduli were increased even more for higher nano-clay loadings, which is in agreement with the findings of Lan and Pinnavaia [34]. Exfoliated clay platelets with $1 \mathrm{~nm}$ thick silicate layers having high in-plane bond strength and large surface area were expected to greatly improve mechanical properties of the nanocomposites [34]. The present study substantiated this notion as even predominantly intercalated nanocomposites generated significantly increased epoxy stiffness; to a certain extent, the intercalated particles of relatively small size caused a stiffening effect similar to that of exfoliated nano-clays.

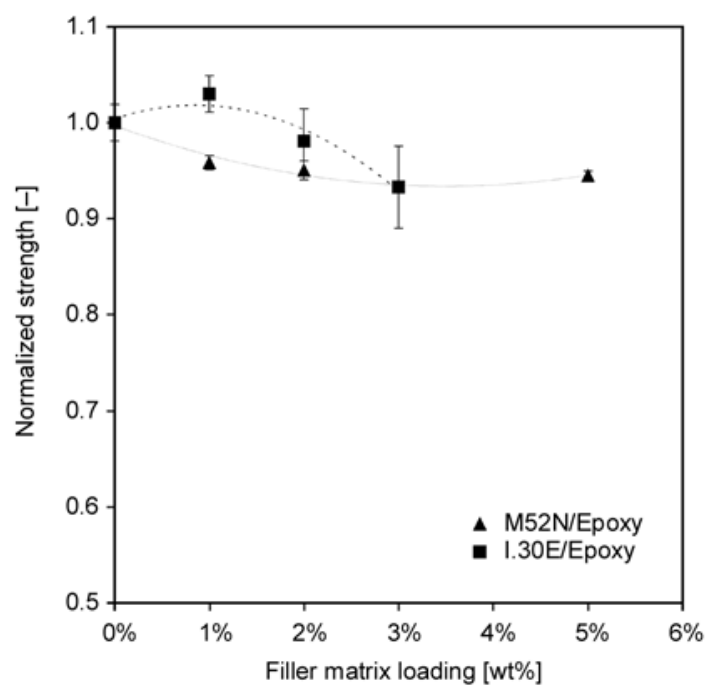

Figure 9. Tensile strength of nanocomposites with respect to nanofiller loading 
Figure 9 correlates tensile strength of the nanocomposites with their corresponding nanofiller loadings. Notably, strength remained mostly unaffected by the block-copolymer addition, which is contrary to the common intuition about rubber modified thermosets $[13,14]$. Possible reasons for this behavior are the nano-scale dispersion and greater compatibility of M52N block-copolymer towards epoxy. Addition of $1 \mathrm{wt} \%$ I.30E nano-clay in the matrix caused a slight increase in tensile strength but for higher nano-clay loadings a minor decrease was recorded.

\subsection{Fractographic study}

SENB fracture surfaces of the neat epoxy and its nanocomposites were extensively studied using SEM microscopy, see Figures 10 and 11. An arrow displayed in these micrographs indicates the crack propagation direction. The neat epoxy fracture surface was found to be flat and smooth, which is characteristic of brittle fracture behavior in a homogenous material. Relative to the unmodified epoxy, the extensively rough surface morphology of the nano-clay filled epoxy evidences repeated perturbation of the crack front from its original propagation path due to the presence of intercalated clay. Features shown in Figure 10b are consistent with bifurcation and/or deflection of the primary crack into multiple secondary cracks which are not necessarily coplanar [25]. Most of the clay tactoids shown in the micrographs are in the submicron size, but it is evident that a small fraction of particles were as large as $\sim 10 \mu \mathrm{m}$. Due to the mostly small particle size and an apparently lower interparticle distance, deflected crack paths intersecting with each other generate a severely textured surface morphology as shown in Figures 10b and 10c, even though the clay concentrations were different for these nanocomposites. No indication of interfacial debonding between the epoxy network and the clay structures was discernible, suggesting excellent interfacial interaction. The morphology of the fracture surface also discounts the occurrence of effective crack pinning mechanisms. As reported in $[25,31]$, crack deflection mechanisms are not an efficient source of toughening, which correlates well with the rather insignificant toughening effect of the nano-clay. In Figures 11a and 11b, acrylic block-copolymer modified epoxy exhibits a plane and featureless

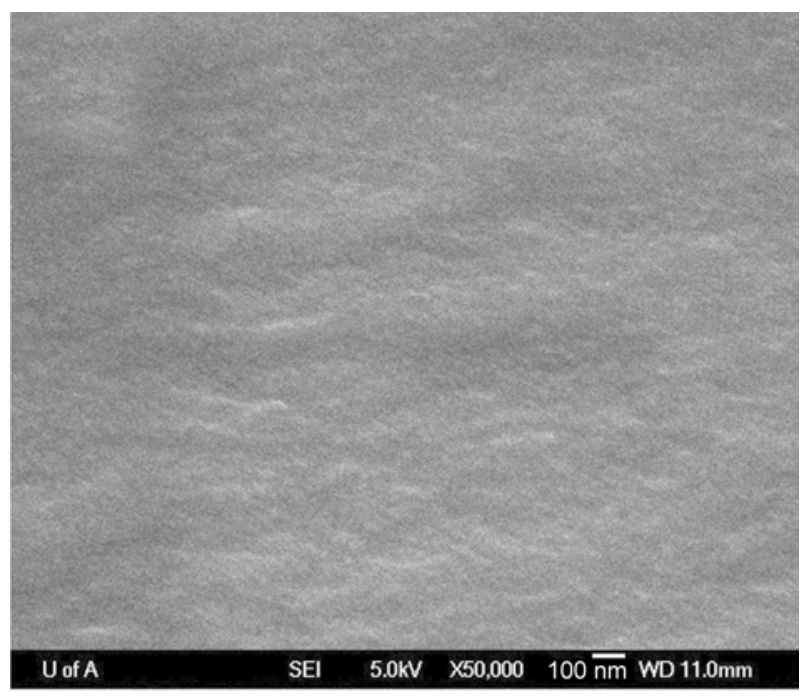

a)

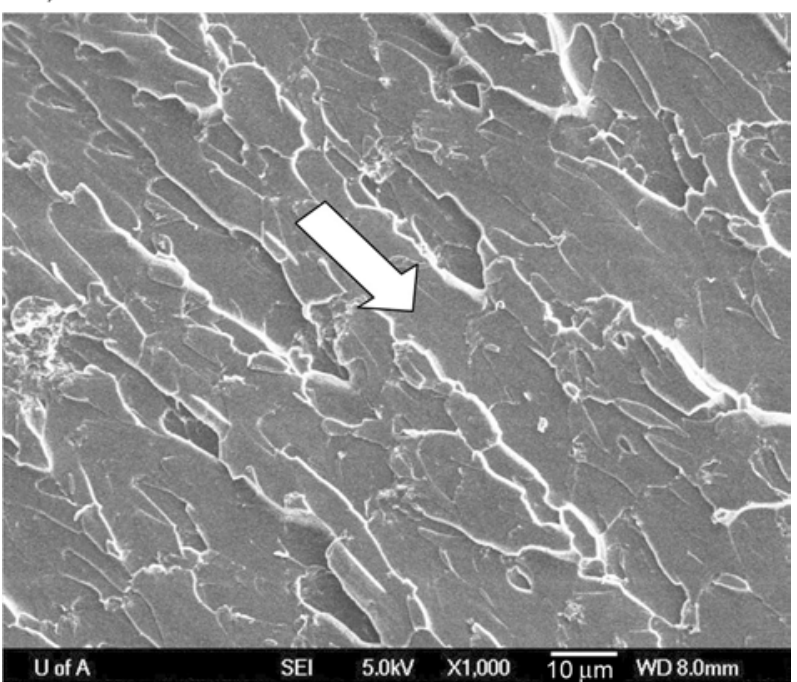

b)

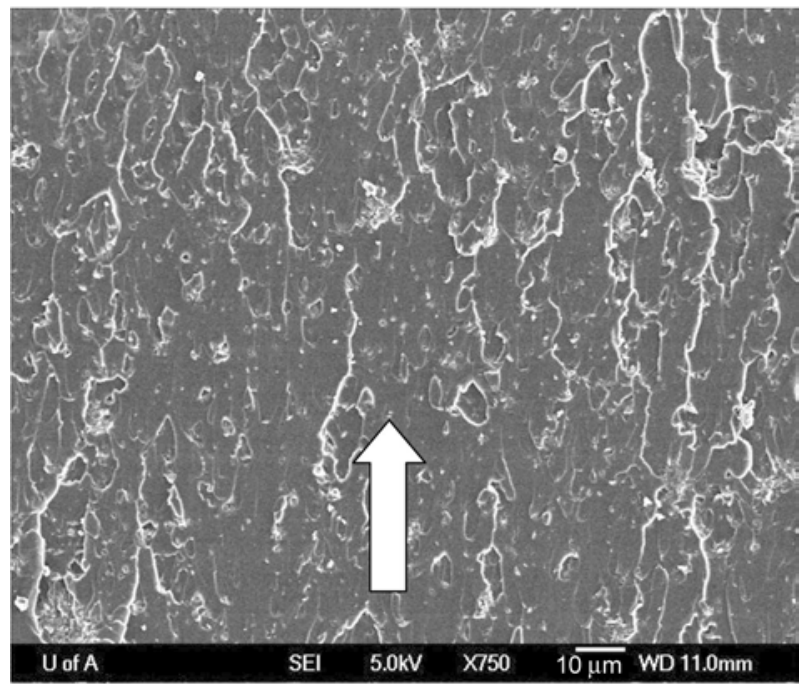

c)

Figure 10. SEM images of nanocomposite fracture surfaces: a) neat epoxy, b) $1 \mathrm{wt} \%$ and c) $2 \mathrm{wt} \%$ I.30E nano-clay modified epoxy 


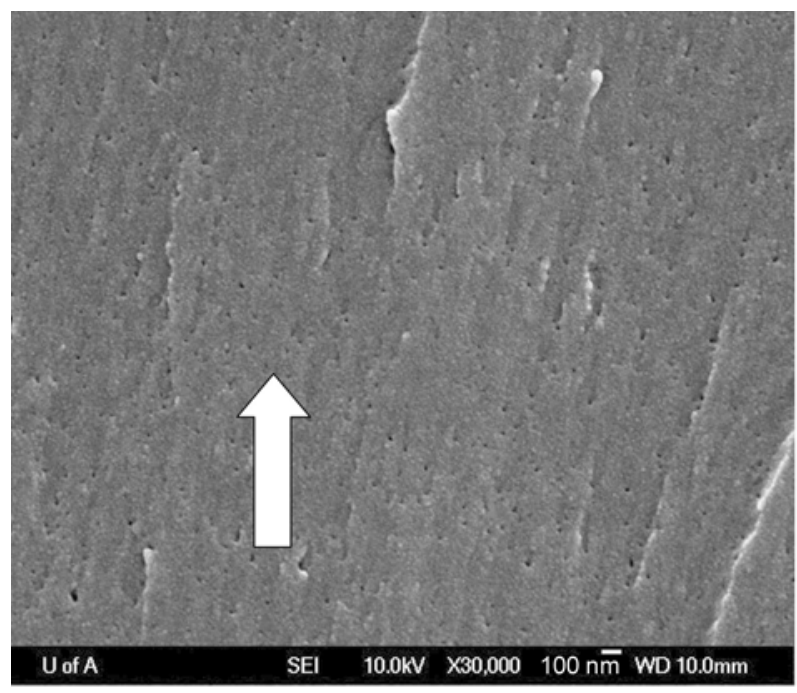

a)

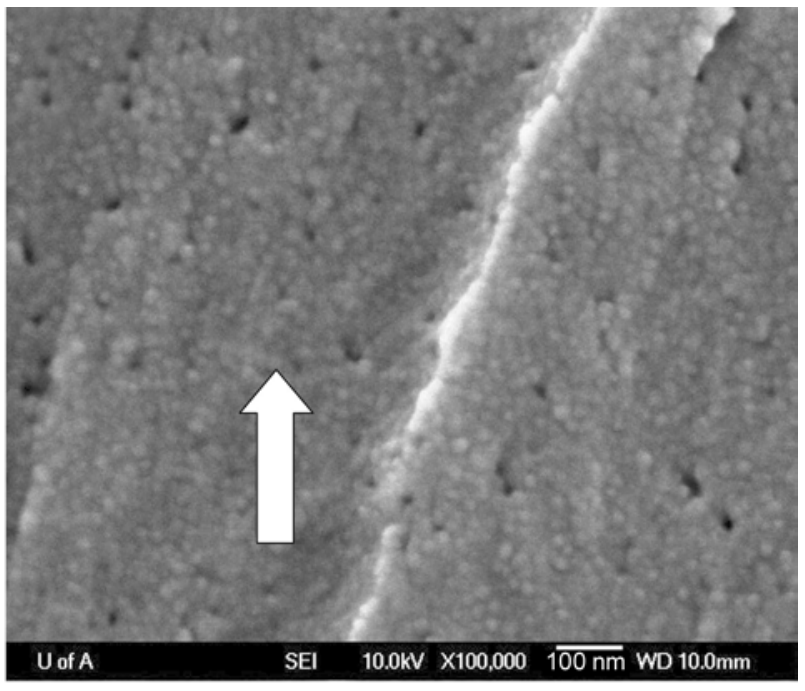

b)

Figure 11. SEM images of M52N block-copolymer modified epoxy fracture surfaces at: a) low magnification and b) high magnification

crack surface with considerable epoxy-rich regions. Also evident in the same pictures is nanoscopic surface roughness. It appears that cavitation of the spherical micelles occurred during the fracture process, which is substantiated by the presence of minute spherical cavities with approximately $\sim 20 \mathrm{~nm}$ size that are randomly dispersed in the polymer matrix. As mentioned previously, the cavitation process is considered to have initiated localized shear yielding of the matrix causing substantial dissipation of energy as evidenced by excellent improvements in fracture toughness [21, 23].

\subsection{Mechanical testing of hybrid nanocomposite tubes}

It is a common inference that transverse matrix cracking initiates near or at the fiber-matrix interface and then transmits through the resin matrix. Matrix cracks usually initiate at very low global strain levels due to high strain concentrations near the fiber resulting from the elastic discontinuity at the interface $[1,37]$. Figure 12 depicts the influence of nanofiller loadings on maximum hoop strain, which usually is congruent with the leakage point at this loading ratio. Maximum hoop strain of the unmodified epoxy pipes was measured to occur at a mechanical strain of approximately $2400 \mu \varepsilon$. For a $5 \mathrm{wt} \%$ M $52 \mathrm{~N}$ loading an increase in leakage failure strain of about $30 \%$ was observed. M52N significantly enhanced leakage failure strain and at the same time reduced stress non-linearity. These results correspond to those reported by Sjögren and

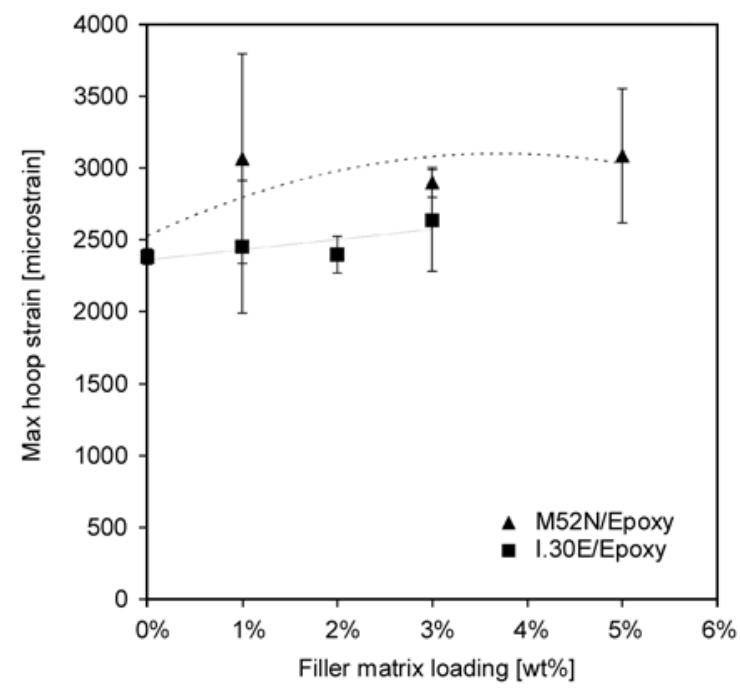

Figure 12. Maximum hoop strain of hybrid nanocomposite pipes as a function of nanofiller loading

Berglund [10,11], who demonstrated a significant increase in transverse cracking strains as a direct consequence of the modifier concentration. Conversely, for nano-clay modified pipes the leakage failure strain remained practically unaffected, and a maximum of $10 \%$ increase in strain was observed for $3 \mathrm{wt} \%$ nano-clay in the matrix.

Failure stresses of hybrid fiber-reinforced nanocomposite pipes are summarized in Figures 13 and 14. The graph for M52N block-copolymer filled epoxy reveals that the hoop stress at leakage increased by only $4 \%$ with the addition of $1 \%$ M52N (Figure 13). For the remainder of block-copolymer concentrations a less pronounced effect on leakage strength was noticed, and a simultaneous decrease in leak- 


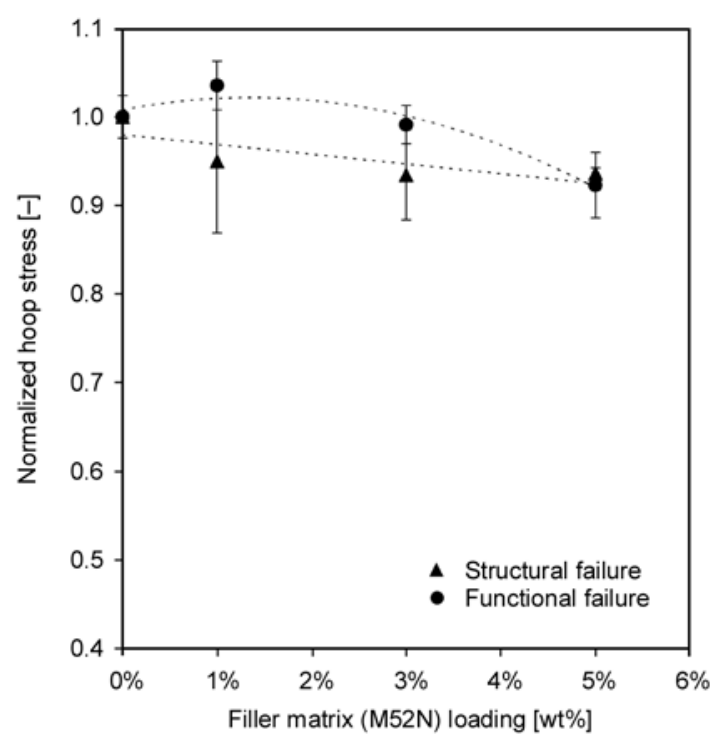

Figure 13. Hoop failure stress of hybrid nanocomposite pipes as a function of M52N block-copolymer loading

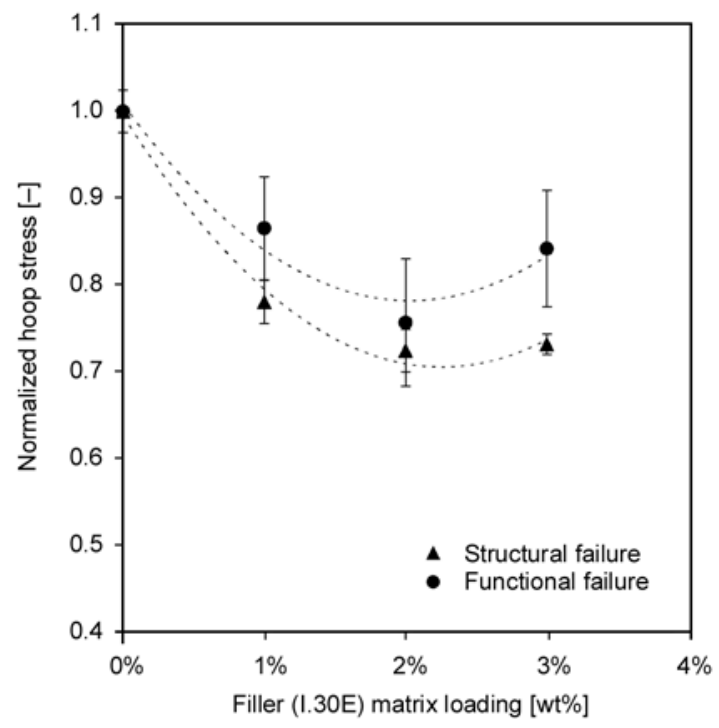

Figure 14. Hoop failure stress of hybrid nanocomposite pipes as a function of I.30E nano-clay loading

age and burst strength was observed for $5 \mathrm{wt} \%$ M52N. Test data for tubes made with I.30E modified polymer showed that the nano-clay imparted significant reductions in both the leakage and burst failure strengths (Figure 14). In summary, failure strength reductions were strongly correlated with I.30E loading, whereas strength values remained relatively stable when the polymer matrix was reinforced with M52N block-copolymer.

For pipes made with pure epoxy it was observed that transverse cracks initiate at low global strain in zones of high fiber packing followed by sudden unstable crack growth. Crack initiation likely occurred by adhesive debonding at the fiber-matrix interface where local strain concentrations are high. Transverse cracking associated with interfacial debonding was observed by various researchers $[10$, 11], and others have described the instantaneous crack propagation phenomenon $[38,39]$. In the case of block-copolymer modified epoxy, the enhanced matrix ductility caused a build-up of strain energy until the sudden release of this energy resulted in initiation and subsequent crack propagation. It appears that matrix toughness significantly affected crack initiation and/or debonding processes due to improved polymer ductility. Delayed debonding may also be the outcome of better interfacial adhesion between the fiber and the matrix [11], possibly due to a sizing effect of the [PMMA/DMA-PBuAPMMA/DMA] block-copolymer on the basalt fiber material [40]. As a consequence, increased strains at leakage failure were observed. However, the influence of M52N block-copolymer addition on the amount and/or extent of cracking was insignificant as evidenced by only minor improvements in leakage failure stresses. It is assumed that restrictions imposed by adjacent fibers on the crack-tip plastic zone affected the propagation of transverse cracks, and also restricted the ability of the spherical micelles to cavitate and cause matrix shear yielding. It has been reported that in a fiber-polymer composite, fibers appear to constrain the crack-tip deformation zone [32]. This effect is more pronounced in a toughened polymer than in a brittle matrix. As a result, the development of matrix crack networks and associated fluid leakage was not diminished anywhere near the extent that one may have expected based on fracture toughness improvements in pure block-copolymer modified epoxy resin.

Influenced by congruent trends between composite pipe leakage strengths and fracture energies ascertained for nanocomposite samples with a blunt crack, it was hypothesized that transverse matrix cracking in filament-wound pipes, which includes both the initiation and propagation of micro-cracks, resembles tensile fracture behavior in a brittle matrix material. As discussed by Subramaniyan and Sun [29] it appears that fracture behavior associated with propagation of blunt cracks is dominated by a stress concentration factor and not a stress intensity 
factor at failure. It is postulated that to some extent these mechanisms were effective in the case of block-copolymer modified epoxy pipes. Further studies are underway in support of this statement, and interlaminar fracture toughness, microscopy studies and interface effects will be discussed in subsequent publications.

For the nano-clay modified epoxy material it was concluded that the presence of few flocculated clay particles provided an uneven distribution of stress concentration points throughout the epoxy matrix (see Figure 4b), which supposedly acted as initiation sites for transverse matrix cracks [18]. Considering that the leakage phenomenon is dominated by crack initiation events rather than crack propagation (of a dominant crack), and due to enhanced stress fields resulting from the interaction of clay aggregates and the applied loading, leakage strength of the composite pipes was degraded. Substantial matrix cracking further caused reduced structural strength. In the presence of a weakened fiber-matrix loadsharing mechanism, fibers failed at their weakest points at reduced global load levels. The degraded matrix also allowed fibers to realign along the direction of the resulting force, thus imposing additional loading upon the fibers.

\section{Conclusions}

Visual inspection of functionally failed fiber-reinforced composite pressure pipes commonly reveals multiple aligned, nearly homogenously distributed cracks, which form numerous interconnected fluid pathways from the inner to the outer pipe surface. The majority of these cracks are oriented parallel to the fiber direction with crossover undulation points indicating delimitation of the laminates. The common intuition about transverse matrix cracking is that it is the consequence of stress acting transverse to the fiber direction. For the fiber orientation selected in this study, it is presumably the axial tensile load which is predominantly responsible for transverse matrix cracking of the composite pipe. Based on these observations the notion was to reinforce the relatively brittle epoxy matrix with a nano-particulate phase with the intent to mitigate the progression of micro-cracks. Yet, the intended reinforcement effect could not be realized, despite a considerable improvement in fracture toughness for one type of the tested nanocomposite system.
Modification of epoxy with tri-block-copolymer M52N rendered significant improvements of epoxy toughness by a process of particle cavitation and localized shear deformation of the matrix. In contrast, I.30E clay exhibited almost negligible influence on epoxy toughness, where the fracture properties of the nanocomposites are dictated by the exfoliated and intercalated morphology of the clay. It was hypothesized that the transverse cracking process for fiber composite pipes made with M52N block-copolymer toughened epoxy begins with prolonged straining followed by fiber-matrix interfacial debonding and immediate crack propagation. Crack progression was also effected by alteration of the crack-tip stress field by adjacent fibers. In case of the I.30E nano-clay modified epoxy pipes, transverse matrix cracking was further accelerated in the presence of micron size clay aggregates which acted as stress concentrators. Even though leakage failure strain improved moderately for some of the hybrid nanocomposite pipes, these enhancements proved insignificant for the leakage failure strength, and the damage mechanism was found to practically resemble that of the neat epoxy composite pipes.

\section{References}

[1] Jones M. L. C., Hull D.: Microscopy of failure mechanisms in filament-wound pipe. Journal of Materials Science, 14, 165-174 (1979). DOI: $10.1007 / \mathrm{BF} 01028340$

[2] Ellyin F., Carroll M., Kujawski D., Chiu A. S.: The behavior of multidirectional filament wound fibreglass epoxy tubulars under biaxial loading. Composites Part A: Applied Science and Manufacturing, 28, 781-790 (1997). DOI: $10.1016 / \mathrm{S} 1359-835 \mathrm{X}(97) 00021-3$

[3] Martens M., Ellyin F.: Biaxial monotonic behavior of a multidirectional glass fiber epoxy pipe. Composites Part A: Applied Science and Manufacturing, 31, 10011014 (2000). DOI: $\underline{10.1016 / \mathrm{S} 1359-835 \mathrm{X}(00) 00041-5}$

[4] Meijer G., Ellyin F.: A failure envelope for $\pm 60^{\circ}$ filament wound glass fibre reinforced epoxy tubulars. Composites Part A: Applied Science and Manufacturing, 39, 555-564 (2008).

DOI: 10.1016/j.compositesa.2007.11.002

[5] Mertiny P., Ellyin F., Hothan A.: An experimental investigation on the effect of multi-angle filament winding on the strength of tubular composite structures. Composites Science and Technology, 64, 1-9 (2004). DOI: $10.1016 / \mathrm{S} 0266-3538(03) 00198-2$ 
[6] Mertiny P., Ellyin F.: Influence of the filament winding tension on physical and mechanical properties of reinforced composites. Composites Part A: Applied Science and Manufacturing, 33, 1615-1622 (2002).

DOI: $10.1016 / \mathrm{S} 1359-835 \mathrm{X}(02) 00209-9$

[7] Hsieh T. H., Kinloch A. J., Masania K., Sohn Lee J., Taylor A. C., Sprenger S.: The toughness of epoxy polymers and fibre composites modified with rubber microparticles and silica nanoparticles. Journal of Materials Science, 45, 1193-1210 (2010).

DOI: $10.1007 / \mathrm{s} 10853-009-4064-9$

[8] Kinloch A. J., Shaw S. J., Tod D. A., Hunston D. L.: Deformation and fracture behaviour of a rubber-toughened epoxy: 1. Microstructure and fracture studies. Polymer, 24, 1341-1353 (1983).

DOI: $10.1016 / 0032-3861(83) 90070-8$

[9] Sultan J. N., McGarry F. J.: Effect of rubber particle size on deformation mechanisms in glassy epoxy. Polymer Engineering and Science, 13, 29-34 (1973). DOI: $10.1002 /$ pen.760130105

[10] Sjögren B. A., Berglund L. A.: Toughening mechanisms in rubber-modified glass fiber/unsaturated polyester composites. Polymer Composites, 20, 705-712 (1999). DOI: $10.1002 / p c .10394$

[11] Sjögren B. A., Berglund L. A.: The effects of matrix and interface on damage in GRP cross-ply laminates. Composites Science and Technology, 60, 9-21 (2000). DOI: 10.1016/S0266-3538(99)00096-2

[12] Pearson R. A., Yee A. F.: Toughening mechanisms in elastomer-modified epoxies. Part 2. Microscopy studies. Journal of Materials Science, 21, 2475-2488 (1986). DOI: $10.1007 / \mathrm{BF} 01114294$

[13] Yee A. F., Pearson R. A.: Toughening mechanisms in elastomer-modified epoxies. Part 1. Mechanical studies. Journal of Materials Science, 21, 2462-2474 (1986). DOI: $10.1007 / \mathrm{BF} 01114293$

[14] Höfflin F., Könczöl L., Döll W., Morawiec J., Mülhaupt R.: Toughening of epoxy resins modified with polyetherester block copolymers: The influence of modifier molecular architecture on mechanical properties. Journal of Applied Polymer Science, 76, 623-634 (2000).

DOI: $10.1002 /($ SICI) 1097-4628(20000502)76:5<623:: AID-APP3>3.0.CO;2-Z

[15] Kinloch A. J., Yuen M. L., Jenkins S. D.: Thermoplastic-toughened epoxy polymers. Journal of Materials Science, 29, 3781-3790 (1994).

DOI: $10.1007 / \mathrm{BF} 00357349$

[16] Bécu-Longuet L., Bonnet A., Pichot C., Sautereau H., Maazouz A.: Epoxy networks toughened by core-shell particles: Influence of the particle structure and size on the rheological and mechanical properties. Journal of Applied Polymer Science, 72, 849-858 (1999). DOI: 10.1002/(SICI)1097-4628(19990509)72:6<849:: AID-APP10>3.3.CO;2-I
[17] Lin K-F., Shieh Y-D.: Core-shell particles designed for toughening the epoxy resins. II. Core-shell-particletoughened epoxy resins. Journal of Applied Polymer Science, 70, 2313-2322 (1998).

DOI: $10.1002 /(\mathrm{SICI}) 1097-4628(19981219) 70: 12<2313$

$$
\because: \mathrm{AID}-\mathrm{APP} 2>3.0 . \mathrm{CO} ; 2-\mathrm{P}
$$

[18] Marouf B. T., Pearson R. A., Bagheri R.: Anomalous fracture behavior in an epoxy-based hybrid composite. Materials Science and Engineering: A, 515, 49-58 (2009).

DOI: $10.1016 /$ j.msea.2009.03.028

[19] Dean J. M., Lipic P. M., Grubbs R. B., Cook R. F., Bates F. S.: Micellar structure and mechanical properties of block copolymer-modified epoxies. Journal of Polymer Science Part B: Polymer Physics, 39, 29963010 (2001).

DOI: $10.1002 /$ polb.10062

[20] Dean J. M., Grubbs R. B., Saad W., Cook R. F., Bates F. S.: Mechanical properties of block copolymer vesicle and micelle modified epoxies. Journal of Polymer Science Part B: Polymer Physics, 41, 2444-2456 (2003). DOI: $10.1002 /$ polb.10595

[21] Hydro R. M., Pearson R. A.: Epoxies toughened with triblock copolymers. Journal of Polymer Science Part B: Polymer Physics, 45, 1470-1481 (2007).

DOI: $10.1002 /$ polb. 21166

[22] Gerard P., Boupat N. P., Fine T., Gervat L., Pascault JP.: Toughness properties of lightly crosslinked epoxies using block copolymers. Macromolecular Symposia, 256, 55-64 (2007).

DOI: $10.1002 /$ masy.200751006

[23] Wu J., Thio Y. S., Bates F. S.: Structure and properties of PBO-PEO diblock copolymer modified epoxy. Journal of Polymer Science Part B: Polymer Physics, 43, 1950-1965 (2005).

DOI: $10.1002 /$ polb.20488

[24] Moloney A. C., Kausch H. H., Stieger H. R.: The fracture of particulate-filled epoxide resins. Journal of Materials Science, 18, 208-216 (1983).

DOI: $10.1007 / \mathrm{BF} 00543827$

[25] Lee J., Yee A. F.: Role of inherent matrix toughness on fracture of glass bead filled epoxies. Polymer, 41, 83758385 (2000).

DOI: $10.1016 / \mathrm{S} 0032-3861(00) 00186-5$

[26] Zilg C., Mülhaupt R., Finter J.: Morphology and toughness/stiffness balance of nanocomposites based upon anhydride-cured epoxy resins and layered silicates. Macromolecular Chemistry and Physics, 200, 661-670 (1999).

DOI: 10.1002/(SICI)1521-3935(19990301)200:3<661:: AID-MACP661>3.0.CO;2-4

[27] Zerda A. S., Lesser A. J.: Intercalated clay nanocomposites: Morphology, mechanics, and fracture behavior. Journal of Polymer Science Part B: Polymer Physics, 39, 1137-1146 (2001). DOI: $10.1002 /$ polb. 1090 
[28] Haque A., Shamsuzzoha M., Hussain F., Dean D.: S2glass/epoxy polymer nanocomposites: Manufacturing, structures, thermal and mechanical properties. Journal of Composite Materials, 37, 1821-1837 (2003). DOI: $10.1177 / 002199803035186$

[29] Subramaniyan A. K., Sun C. T.: Toughening polymeric composites using nanoclay: Crack tip scale effects on fracture toughness. Composites Part A: Applied Science and Manufacturing, 38, 34-43 (2007). DOI: $10.1016 /$ j.compositesa.2006.01.021

[30] Miller S. G., Meador M. A.: Polymer-layered silicate nanocomposites for cryotank applications. in " $48^{\text {th }}$ AIAA/ASME/ASCE/AHS/ASC Structures, Structural Dynamics, and Material Conference, Waikiki, USA' Vol 8, 7530-7538 (2007).

[31] Garg A. C., Mai Y-W.: Failure mechanisms in toughened epoxy resins - A review. Composites Science and Technology, 31, 179-223 (1988). DOI: 10.1016/0266-3538(88)90009-7

[32] Hunston D. L.: Composite interlaminar fracture: Effect of matrix fracture energy. Journal of Composites Technology and Research, 6, 176-180 (1984).

DOI: $10.1520 / C T R 10842 J$

[33] Bradley W. L.: Understanding the translation of neat resin toughness into delamination toughness in composites. Key Engineering Materials, 37, 161-198 (1989). DOI: $10.4028 /$ www.scientific.net/KEM.37.161

[34] Lan T., Pinnavaia T. J.: Clay-reinforced epoxy nanocomposites. Chemistry of Materials, 6, 2216-2219 (1994). DOI: $\underline{10.1021 / \mathrm{cm} 00048 \mathrm{a} 006}$
[35] Bashar M. T., Mertiny P.: Performance of hybrid fiberreinforced polymer nanocomposite pipes. in 'SAMPE 2010 Conference and Exhibition, Seattle, USA' p6 (2010).

[36] Messersmith P. B., Giannelis E. P.: Synthesis and characterization of layered silicate-epoxy nanocomposites. Chemistry of Materials, 6, 1719-1725 (1994).

DOI: $10.1021 / \mathrm{cm} 00046 \mathrm{a} 026$

[37] Asp L. E., Berglund L. A., Talreja R.: Prediction of matrix-initiated transverse failure in polymer composites. Composites Science and Technology, 56, 10891097 (1996). DOI: $10.1016 / 0266-3538(96) 00074-7$

[38] Wang A. S. D.: Fracture mechanics of sublaminate cracks in composite materials. Journal of Composites Technology and Research, 6, 45-62 (1984). DOI: $10.1520 /$ CTR10817J

[39] Parvizi A., Garrett K. W., Bailey J. E.: Constrained cracking in glass fibre-reinforced epoxy cross-ply laminates. Journal of Materials Science, 13, 195-201 (1978).

DOI: $10.1007 / \mathrm{BF} 00739291$

[40] Li Y., Lin Q., Chen L., Zhou X.: Assembly of triblock copolymer brush at glass fiber/polystyrene interface and its effect on interfacial shear strength. Composites Science and Technology, 69, 1919-1924 (2009). DOI: $10.1016 /$ j.compscitech.2009.04.008 